\title{
OPEN Facile one-pot green synthesis of Ag-ZnO Nanocomposites using potato peeland their Ag concentration dependent photocatalytic properties
}

Fahad A. Alharthi ${ }^{1,3 凶}$, Abdulaziz Ali Alghamdi ${ }^{1,3}$, Nabil Al-Zaqri $^{1}$, Hamdah S. Alanazi ${ }^{1}$, Amjad Abdullah Alsyahi ${ }^{1}$, Adel El Marghany ${ }^{1,2}$ \& Naushad Ahmad ${ }^{1}$

Herein, a facile green synthesis route was reported for the synthesis of $\mathrm{Ag}-\mathrm{ZnO}$ nanocomposites using potato residue by simple and cost effective combustion route and investigated the photocatalytic degradation of methylene blue (MB) dye. In the preparation potato extract functioned as a biogenic reducing as well as stabilizing agent for the reduction of $\mathrm{Ag}+$, thus eliminating the need for conventional reducing/stabilizing agents. Ag-ZnO nanocomposites with different Ag mass fractions ranging from 2 to $10 \%$ were characterized by using XRD, FT-IR, XPS, SEM, TEM, and UVVis spectroscopy. XRD analysis revealed that the as prepared Ag-ZnO nanocomposites possessed high crystallinity with hexagonal wurtzite structure. TEM and SEM images showed that the Ag-ZnO nanocomposites in size ranging from 15 to $25 \mathrm{~nm}$ have been obtained, and the particle size was found to increase with the increase in percentage of Ag. FTIR results confirmed the characteristics band of $\mathrm{ZnO}$ along with the $\mathrm{Ag}$ bands. XPS analysis revealed a pair of doublet with peaks corresponding to $\mathrm{Ag}$ and a singlet with peaks corresponding to $\mathrm{ZnO}$. With the increase of concentration of $\mathrm{Ag}$ in $\mathrm{ZnO}$, the intensity of NBE emission in the PL spectra was observed to be decrease, resulted to the high photocatalytic activity. Photocatalytic properties of $\mathrm{Ag}-\mathrm{ZnO}$ nanocomposites evaluated against the MB dye under visible-light irradiation showed superior photodegradation of $~ 96 \%$ within 80 min for $2 \% \mathrm{Ag}-\mathrm{ZnO}$ nanocomposites. The apparent reaction rate constant for $2 \% \mathrm{Ag}-\mathrm{ZnO}$ nanocomposites was higher than that of other nanocomposites, which proved to be the best photocatalyst for the maximum degradation of MB. Furthermore, various functional parameters such as dosing, reaction medium, concentration variation were performed on it for better understanding. The enhancement in photocatalytic degradation might be due to the presence of Ag nanoparticles on the surface of $\mathrm{ZnO}$ by minimizing the recombination of photo induced charge carriers in the nanocomposites.

Clean and fresh water, which are unevenly distributed on the face of earth, are great need for living beings and our immediate natural environment. Human fluid is significantly made of water (75\%); it is essential medium for many biochemical reactions like dissolution of biomolecules proteins, carbohydrates and important activities such as blood transport, digestion, and electrical charged balanced ${ }^{1}$. It provides healthy habitat for aquatic organisms and plants by capturing of balanced amount of sunlight and finally preserve the water ecosystem. Besides human activities, rapid urbanization, climate change, inefficient water management, and world population, the real contributor for the pollution and reduction of available clean water and natural ecosystem are petroleum, pesticides, toxic heavy metal ions, chemicals, greenhouse gases, personal care products wastes and non-degradable dyestuff released from different kind of industries, factories and houses, which are currently become a serious global challenge for the safety of environmental among scientific communities and regulation authorities ${ }^{2-4}$.

Among various wastewater agents, industrial effluents of dyes from plastics, textile, paint, leather and paper industries are frequently released into the water bodies and causes death of living beings and adverse effects on

${ }^{1}$ Department of Chemistry, College of Science, King Saud University, Riyadh 11451, Kingdom of Saudi Arabia. ${ }^{2}$ Department of Chemistry, Faculty of Science, Suez University, Suez, Egypt. ${ }^{3}$ These authors contributed equally: Fahad A. Alharthi and Abdulaziz Ali Alghamdi. ${ }^{\circledR}$ email: fharthi@ksu.edu.sa 
surroundings by accumulation, which have following harmful features: resistant to degrade on exposure to light, chemicals and water, persistent in nature because of their stable chemical structure, carcinogenic aromatically and mutagenic, comparatively higher toxicity, and sunlight opacity due to the its color ${ }^{5-8}$. Therefore, due to the serious impact of dyes, its mineralization or removal before disposal by sophisticated environmental friendly green routes and effective integration of norms as well as environmental policies are seriously very important for conservation of water system, even though it plays a great role in the economic development of any country, widely used science and technology that can make the human life beautiful.

Among various reported techniques for treatment of wastewater ${ }^{9-11}$, photocatalytic process by the application of nano-ranged materials, complete mineralization of the dyes over its surface, is reliable, high sensitive with reasonable costs and environmentally safe technique ${ }^{12-21}$. Briefly in this process, the nanomaterials illuminated by light of the proper wavelength generate active species, which oxidize the organic compounds dissolved in water. Numerable nanomaterials are applied on wastewater treatment but most of them have low catalysis, adsorption capacity, limitations of photocatalytic efficiency, light absorption, and high production costs ${ }^{22,23}$. The current interest for researcher or pollutant management to improve photocatalytic performance either by changing electronic structural properties such as charge transfer, band gap, morphology and particle size or doping of metal and non-metal ${ }^{23-26}$ in advanced dye-sensitizing nanomaterials. Therefore, it is highly needed to design the appropriate electronic structure or doping of the nanomaterials for potential photocatalytic activity.

One of well-known dye sensitive semiconductor is multifunctional zinc oxide nano-oxide which have capability of not only to degradation of complex-stable dye stuff but also very useful for the removal of other hazardous chemicals because of their unique properties such as optical band gap energy ( $3.37 \mathrm{eV})$, high-exciton binding energy $(60 \mathrm{meV})$, biocompatibility, high-electron communication features ${ }^{27,28}$. Recently $\mathrm{ZnO}$ with various morphologies comprised $0 \mathrm{D}, 1 \mathrm{D}, 2 \mathrm{D}$, and $3 \mathrm{D}^{29-32}$ as well as dopants ${ }^{27,33,34}$ (metal and non-metal dopants) have been prepared with high photocatalytic efficiency.

The response of $\mathrm{ZnO}$ in UV range is well known, while, in order to extend the spectral response of $\mathrm{ZnO}$ in the visible range, anchoring of metal particles on the surface of $\mathrm{ZnO}$ nanostructures have been studied by various researchers. In a report, Georgekutty et al. ${ }^{35}$ reported the use of non-aqueous method, on the other hand, Chen et al. ${ }^{36}$ deposited $\mathrm{Ag}$ on $\mathrm{ZnO}$ by using photochemical reaction to prepare $\mathrm{Ag} / \mathrm{ZnO}$ composite and performed their photocatalytic studies. In another work, Deng et al. ${ }^{37}$ showed that the improvement in charge separation and enhancement in the efficiency of the degradation was ascribed to the Schottky barrier in the regions between $\mathrm{Ag}$ and $\mathrm{ZnO}$. It has been shown that the photogenerated electrons from the semiconductor can be trapped in $\mathrm{Ag}$, which allows holes to form hydroxyl radicals that can then react with the organic species, resulting in their degradation. Nevertheless, most of these reported techniques utilize unsafe chemicals, which can cause a serious damage if persist in the environment. Thus, a novel, safe and cost effective method for the preparation of metal - metal oxide nanocomposites needed.

In recent years, green synthesis as a valuable alternatives route to the chemical methods for the preparation of nanoparticles using natural sources including micro-organisms, plants or plant extracts were suggested ${ }^{38-42}$. Among these, the use of plant extracts has shown enormous interest in the synthesis of nanoparticles. More specifically, the potato is tuberous crop which is well known due to its carbohydrate contents where the predominant form of this carbohydrate is starch. Starch, a natural polymer is abundant, renewable, inexpensive and widely available and could be efficiently used as templates for nanoparticles growth ${ }^{43,44}$.

Keeping above facts in mind, in this work, a facile, green, low-cost and one-pot method for synthesis of $\mathrm{Ag}-\mathrm{ZnO}$ nanocomposites using potato peel without any additives such as reducing agent, acids and organic solvents were reported. The photocatalytic properties of these $\mathrm{Ag}-\mathrm{ZnO}$ nanocomposites containing various concentration $(1 \%, 2 \% 8 \%, 10 \%)$ of $\mathrm{Ag}$ in $\mathrm{ZnO}$ were investigated by measuring the degradation of $\mathrm{MB}$ under visible light irradiation. Various parameters such as effect of Ag concentration, catalyst dosage, MB dye concentrations, and $\mathrm{pH}$ on dye degradation were also presented. Based on the obtained results and their discussions, a possible mechanism related to the degradation of $\mathrm{MB}$ dye with $\mathrm{Ag}-\mathrm{ZnO}$ nanocomposites has been discussed investigated in detail. The experimental results showed that the as-obtained $\mathrm{ZnO}$ nanorods with $2 \% \mathrm{Ag}$ in $\mathrm{ZnO}$ exhibited excellent photocatalytic activity than other nanocomposites. This study will provide the platform to synthesize $\mathrm{ZnO}$ based nanocomposites by route using potato or other biomaterial by green method, and the photocatalytic properties could be easily tuned for future applications. We believe that this simple and one-step method can suitably be scaled up for large-scale synthesis.

\section{Materials and methods}

The chemicals such as zinc nitrate hexahydrate $\left(\mathrm{Zn}\left(\mathrm{NO}_{3}\right)_{2} \cdot 6 \mathrm{H}_{2} \mathrm{O}\right)$, silver Nitrate $\left(\mathrm{AgNO}_{3}\right)$, Methylene Blue dye (MB), were purchased from Sigma-Aldrich-Germany and used as received. The glassware was used with analytical boro-silicate grade.

Experimental details. Synthesis of $\mathrm{Ag}-\mathrm{ZnO}$ nanocomposites using potato peels. Fine powder of potato peels $(0.594 \mathrm{~g})$ was mixed with $0.291 \mathrm{~g} \mathrm{Zn}\left(\mathrm{NO}_{3}\right)_{2} \cdot 6 \mathrm{H}_{2} \mathrm{O}$ (99.999\%, Sigma-Aldrich-Germany) and $1 \mathrm{wt} \% \mathrm{AgNO}_{3}$ (99.999\%, Sigma-Aldrich-Germany) had been taken in borosil glass container. After adding $10 \mathrm{~mL}$ deionized water, the solution was stirred for $10 \mathrm{~min}$ on a hot plate at $70{ }^{\circ} \mathrm{C}$. The resulting solution was centrifuged, washed with DI water and dried at $50{ }^{\circ} \mathrm{C}$. The as-prepared product was further heated in air in a muffle furnace at $500{ }^{\circ} \mathrm{C}$ for $10 \mathrm{~min}$ to obtain $\mathrm{Ag}-\mathrm{ZnO}$ nanocomposites. The obtained product was used for the characterizations. Similarly, other compositions namely $2 \% \mathrm{Ag}-\mathrm{ZnO}$ nanocomposites, $8 \% \mathrm{Ag}-\mathrm{ZnO}$ nanocomposites, and $10 \%$ $\mathrm{Ag}-\mathrm{ZnO}$ nanocomposites were prepared and characterized in terms of their morphological, structural and optical properties, and were used as photocatalysts for the mineralization of toxic MB dye. 


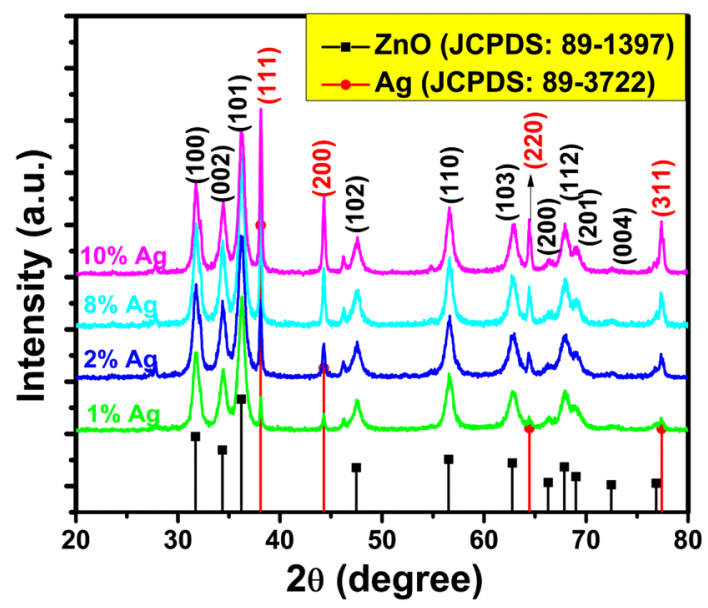

Figure 1. XRD patterns for Ag- $\mathrm{ZnO}$ nanocomposites (a) $1 \%$, (b) $2 \%$, (c) $8 \%$, (d) $10 \% \mathrm{Ag}$.

Characterization. The crystallinity of fine powders was recorded through X-ray diffractometer (Rigaku Ultimate $1 \mathrm{~V}$, Japan) with $\mathrm{Cu}_{\mathrm{Ka}}$ radiation source $(\lambda=1.5417 \AA)$ in $2 \theta$ range of $10-80^{\circ}$. The Fourier transform infrared spectroscopy (FTIR, Bruker Vertex 70, Germany) measurements were conducted from the range of $4000-400 \mathrm{~cm}^{-1}$ with $\mathrm{KBr}$ pellet method at room temperature. The morphological aspects and particle size of fabricated catalysts were examined with scanning electron microscope (SEM) (JEOL JSM7600F, Japan) and transmission electron microscope (TEM, JEOL-21000F, Japan). The chemical states and surface element composition were determined by X-ray photoelectron (XPS) in omicron with a monochromatic $\mathrm{Al}_{\mathrm{Ka}}$ radiation source and charge neutralizer. The $\mathrm{C} 1 \mathrm{~s}$ line was taken as an internal standard at $284.6 \mathrm{eV}$. Both wide-range survey spectra and detailed spectra (for $\mathrm{Ag} 3 \mathrm{~d}, \mathrm{Zn} 2 \mathrm{p}, \mathrm{O}$ 1s and C 1s) were collected at $300 \mathrm{~W}$.

Photocatalytic activity measurements. For the photocatalytic properties of $\mathrm{Ag}-\mathrm{ZnO}$ nanocomposites, $\mathrm{MB}$ was chosen as water pollutant modal. Degradation of $\mathrm{MB}$ by $\mathrm{Ag}-\mathrm{ZnO}$ nanocomposites were carried out in a photocatalytic reactor, which consist of a $250 \mathrm{~W}$ visible lamp and $37 \mathrm{~cm}$ long quartz tube of $100 \mathrm{ml}$ capacity. Aqueous solution $(5 \mathrm{ppm})$ of the $\mathrm{MB}$ and fabricated catalyst $(10 \mathrm{mg})$ was photocatalyzed in a quartz reactor at room temperature under the UV light irradiation. The prepared suspension was sonicated in the dark for the dispersion and establishment of adsorption-desorption between the MB and the catalyst before irradiation. After that $2 \mathrm{ml}$ centrifuged solution was taken out from reactor and its absorbance was recorded at UV-Vis spectrophotometer by monitoring $664 \mathrm{~nm}$ wavelength in the range of $200-800 \mathrm{~nm}$ for $80 \mathrm{~min}$. A MB solution in absence of any photocatalyst was used as control.

\section{Results and discussions}

X-ray diffraction. Figure 1 shows the XRD patterns of $\mathrm{Ag}-\mathrm{ZnO}$ nanocomposites in which two different sets of XRD pattern were observed associated with Ag and ZnO. The typical hexagonal wurtzite structure with

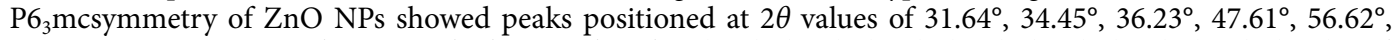
$62.97^{\circ}, 66.45^{\circ}, 67.85^{\circ}$ and $68.97^{\circ}$, which are indexed as (100), (002), (101), (102), (110), (103), (200), (112) and (201) planes, respectively, and well matched with the JCPDS, File No. 036-1451 ${ }^{45}$. In addition, the presence of the four specific peaks at $38.15^{\circ}, 44.36^{\circ}, 64.53^{\circ}$ and $77.39^{\circ}$ clearly matched with (111), (200), (220) and (311) planes of silver (Ag), respectively. All the peaks in XRD pattern can be readily indexed to a face-centered cubic structure of Agas per available literature (JCPDS, File No. 4-0783) ${ }^{46}$, confirmed the presence of Ag in the sample. The peak intensity of $\mathrm{Ag}$ phase for $\mathrm{Ag}-\mathrm{ZnO}$ nanocomposites was intensified and sharper with the increment of $\mathrm{Ag}$ contents, which suggest that Ag metallic phase has been successfully formed on the surface of ZnO-NPs rather than incorporation into the $\mathrm{ZnO}$ lattice. This could be due to the fact that the ionic radius of $\mathrm{Ag}+(126 \mathrm{pm})$ is larger than that of $\mathrm{Zn}^{2+}(74 \mathrm{pm})$, which resulted to the formation of metallic $\mathrm{Ag}$, and no shift in the peak positions of $\mathrm{Ag}-\mathrm{ZnO}$ nanocomposites indicates that $\mathrm{Ag}$ particles are positioned on the surfaces of well crystalline $\mathrm{ZnO}$ $\mathrm{NPs}^{47}$. The crystallite size of the Ag-ZnO nanocomposites calculated using the Scherrer formula ${ }^{45}$ was found to increase from 12 to $20 \mathrm{~nm}$ with the increase of $\mathrm{Ag}$ concentration in $\mathrm{ZnO}$. This increase in crystallite size ascribed to the Ag nanoparticles anchoring on the surface of $\mathrm{ZnO}$.

Fourier transform infrared (FTIR) spectroscopy. The chemical composition in terms of functional groups of the prepared products was analyzed by the FTIR spectroscopy in the range of $400-4000 \mathrm{~cm}^{-1}$ and shown in Fig. 2. A broad band at $3200-3435 \mathrm{~cm}^{-1}$ can be attributed to stretching H-bound water, and 1410$1622 \mathrm{~cm}^{-1}$ can be ascribed to the bending vibrations of the hydroxide $(-\mathrm{OH})$ groups absorbed at the surface of samples ${ }^{48}$. The weak bands observed at 2364,1095 and $1041 \mathrm{~cm}^{-1}$ were related to the vibrations of the organic residuals. The sharpest and dominated absorption band was appeared at $530 \mathrm{~cm}^{-1}$ which might be correlated to 


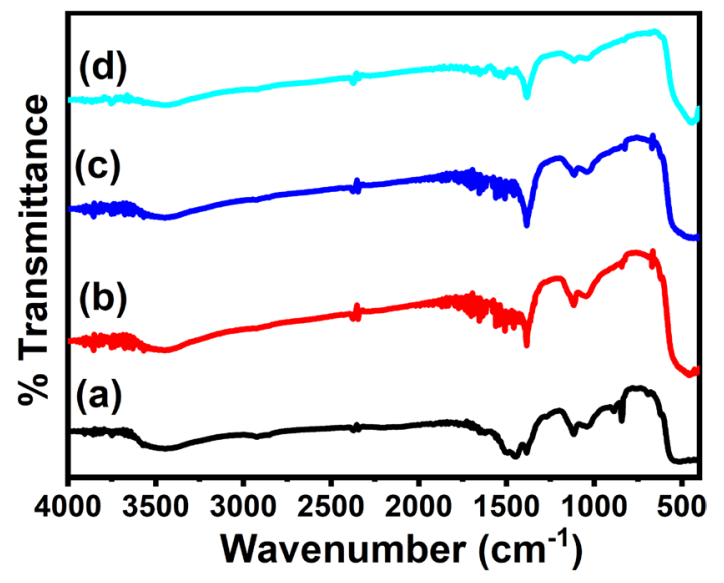

Figure 2. FTIR spectra Ag-ZnO nanocomposites (a) $1 \%$, (b) $2 \%$ (c) $8 \%$, and (d) $10 \% \mathrm{Ag}$.
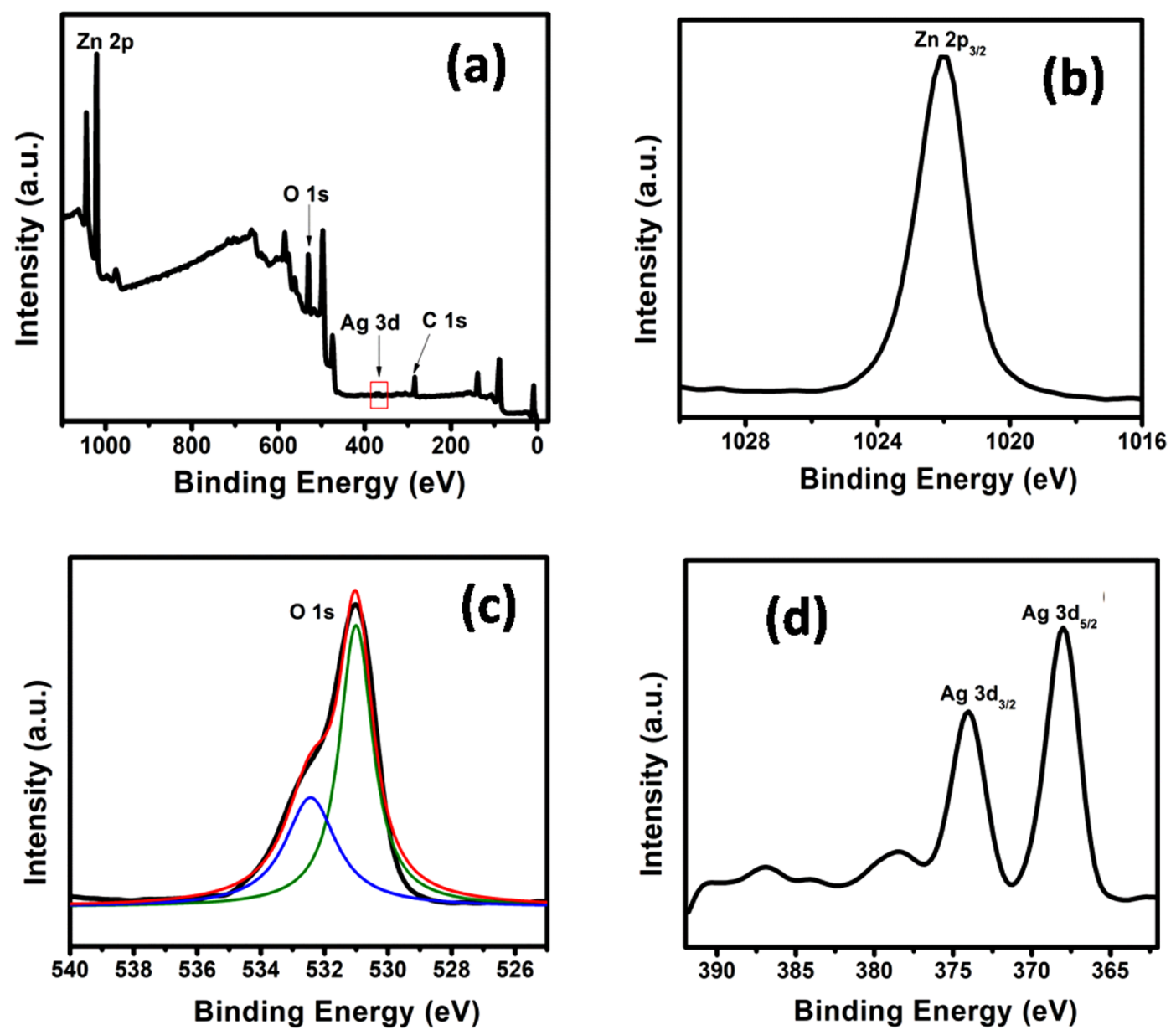

Figure 3. XPS spectra of $2 \% \mathrm{Ag}-\mathrm{ZnO}$ nanocomposites (a) survey, (b) $\mathrm{Zn} 2 \mathrm{p}_{3 / 2}$, (c) O1s, and (d) Ag3d spectra.

the $\mathrm{M}-\mathrm{O}$ bonds $(\mathrm{M}=\mathrm{Zn} \text { and } \mathrm{Ag})^{49}$. No notable shift in the absorption peaks were observed with increasing the Ag concentration but bands became sharpen.

X-ray photoelectron spectroscopy (XPS) analysis. The XPS technique was used to investigate the chemical states and surface composition of $2 \% \mathrm{Ag}-\mathrm{ZnO}-\mathrm{NPs}$ due to its importance in photocatalytic activity. The survey spectra presented in Fig. 3a confirms that $\mathrm{Ag}-\mathrm{ZnO}$ nanocomposites contains the elemental signals from carbon $(\mathrm{C})$, oxygen $(\mathrm{O})$, Zinc $(\mathrm{Zn})$ and silver $(\mathrm{Ag})$ atoms in the sample, which is consisted with the XRD results. 

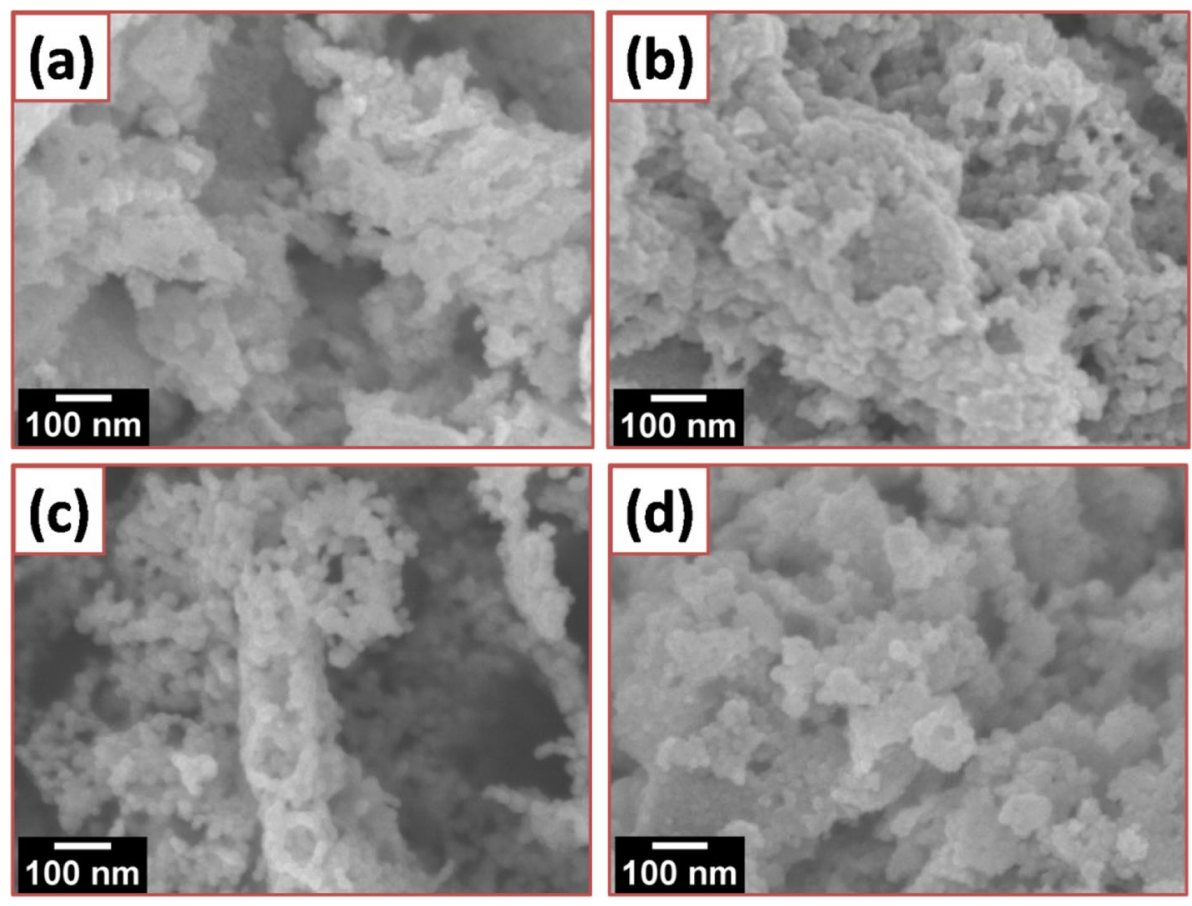

Figure 4. SEM images of different Ag-ZnO nanocomposites (a) $1 \%$, (b) $2 \%$, (c) $8 \%$, and (d) $10 \% \mathrm{Ag}$.

No other impurity elements were observed, which further confirms the high purity of the nanocomposites. The appearance of carbon peak (not shown) $(\mathrm{C} 1 \mathrm{~s}=284.8 \mathrm{eV})$ was mainly related to the residual carbon from the sample as well as the hydrocarbons from the XPS instrument ${ }^{50}$. High resolution spectrum of $\mathrm{Zn} 2 \mathrm{p}, \mathrm{O} 1 \mathrm{~s}$, and Ag $3 \mathrm{~d}$ is shown in Fig. $3 \mathrm{~b}-\mathrm{d}$, where; the binding energies of $\mathrm{Ag}-\mathrm{ZnO}$ nanocomposites are slightly different, revealing a strong interaction between $\mathrm{Ag}$ and $\mathrm{ZnO}$ nanoparticles. As observed in Fig. 3b, there was one peak centered at $1022.06 \mathrm{eV}$ corresponded to the $\mathrm{Zn} 2 \mathrm{p}_{3 / 2}$, indicating a normal state of $\mathrm{Zn}^{2+}$ in the $2 \% \mathrm{Ag}-\mathrm{ZnO}$ nanocomposites. Other peak was centered at $1044.4 \mathrm{eV}$ correspond to the binding energy of $\mathrm{Zn} 2 \mathrm{p}_{1 / 2}$ (see Fig. 3a). O 1s corelevel spectrum (see Fig. 3c) showed two sub-peaks at $532.43 \mathrm{eV}\left(\mathrm{O}_{\mathrm{I}}\right)$ and $530.95 \mathrm{eV}\left(\mathrm{O}_{\mathrm{II}}\right)$. In the XPS spectrum, the peak at high binding energy assigned as $\mathrm{O}_{\mathrm{I}}$ is related with the adsorbed oxygen or hydroxide, however, the peak positioned at lower energy assigned as $\mathrm{O}_{\text {II }}$ peak could be attributed to the lattice oxygen of Ag- $\mathrm{ZnO}$ nanocomposites. During photocatalyst is, surface hydroxyl group tends to plays a major role ${ }^{51}$. Figure $3 \mathrm{~d}$ shows the high resolution spectrum of $\mathrm{Ag} 3 \mathrm{~d}$ deconvoluted into three peaks. The peaks positioned at $374.6 \mathrm{eV}$ and $368.6 \mathrm{eV}$ could be related to the $\mathrm{Ag} 3 \mathrm{~d}_{3 / 2}$ and $\mathrm{Ag} 3 \mathrm{~d}_{5 / 2}$ characteristics for metallic silver $\left(\mathrm{Ag}^{\circ}\right)$, respectively ${ }^{52}$, confirmed the successfully reduction of $\mathrm{Ag}$ ions to produce metallic silver in $\mathrm{Ag}-\mathrm{ZnO}$ nanocomposites.

Morphological study. The SEM images of various composition are shown in Fig. 4a-d confirmed the coexistence of $\mathrm{Ag}$ and $\mathrm{ZnO} \mathrm{NPs}$ in $\mathrm{Ag}-\mathrm{ZnO}$ nanocomposites with a size ranging from 15 to $25 \mathrm{~nm}$. It also shows that the $\mathrm{ZnO}$ has a low density, and a loose material that is favorable for a catalytic application. It is observed that Ag NPs are very small in size at low concentration but lot of Ag aggregated appeared at surface of dispersed and porous $\mathrm{ZnO}$ flower like microforest structures observed, when the amount was increased. To further validate the existence of $\mathrm{Ag}$ NPs, the TEM analysis was performed on the more photocatalytic active sample, $2 \% \mathrm{Ag}-\mathrm{ZnO}$ NPs (Fig. 5a), clearly identify a lot of Ag NPs of small and spherical size (7-12 nm) deposited on ZnO surface. This is probably due to the inhibition of Ag doping towards the crystallization and crystal growth of $\mathrm{ZnONPs}^{53}$. It can be seen that $\mathrm{Ag}$ nanoparticles are anchored on the surface of $\mathrm{ZnO}$, and well distributed over the surface. Figure $5 \mathrm{~b}$ shows the EDX spectrum of $2 \% \mathrm{Ag}-\mathrm{ZnO}$ nanocomposites in which $\mathrm{Zn}, \mathrm{O}$, and $\mathrm{Ag}$ signals were detected, which reveals that nanocomposites contain well distributed Ag in $\mathrm{ZnO}$. In order to further determine the Ag content in $\mathrm{ZnO}$ with various $\mathrm{Ag}$ concentrations, EDX analysis of Ag- $\mathrm{ZnO}$ nanocomposites with different $\mathrm{Ag}$ content was performed and shown in Fig. 6. It is clear from Fig. 6 and the elemental table (insets) that the $\mathrm{Ag}$ content (1\%, $2 \%, 8 \%$, and $10 \%)$ in $\mathrm{ZnO}$ is well matched with elemental analysis, which indicated that $\mathrm{Ag}$ has been successfully incorporated in $\mathrm{ZnO}$.

Optical properties (PL). In order to study the charge recombination and migration efficiency of $\mathrm{Ag}-\mathrm{ZnO}$ nanocomposites, optical properties of $\mathrm{Ag}-\mathrm{ZnO}$ nanocomposites were evaluated using PL technique as the photocatalytic properties are strongly dependent on the PL intensity and the recombination rate of photogenerated charge carriers. Figure 7 shows the room-temperature PL spectra of the Ag- $\mathrm{ZnO}$ nanocompositeswith various concentration of Ag in ZnO. A near-band-edge (NBE) emission at $\sim 393 \mathrm{~nm}$ was observed and the intensity of $\mathrm{NBE}$ emission was found to decrease with the increase of $\mathrm{Ag}$ concentration in $\mathrm{ZnO}$, which suggests that the 

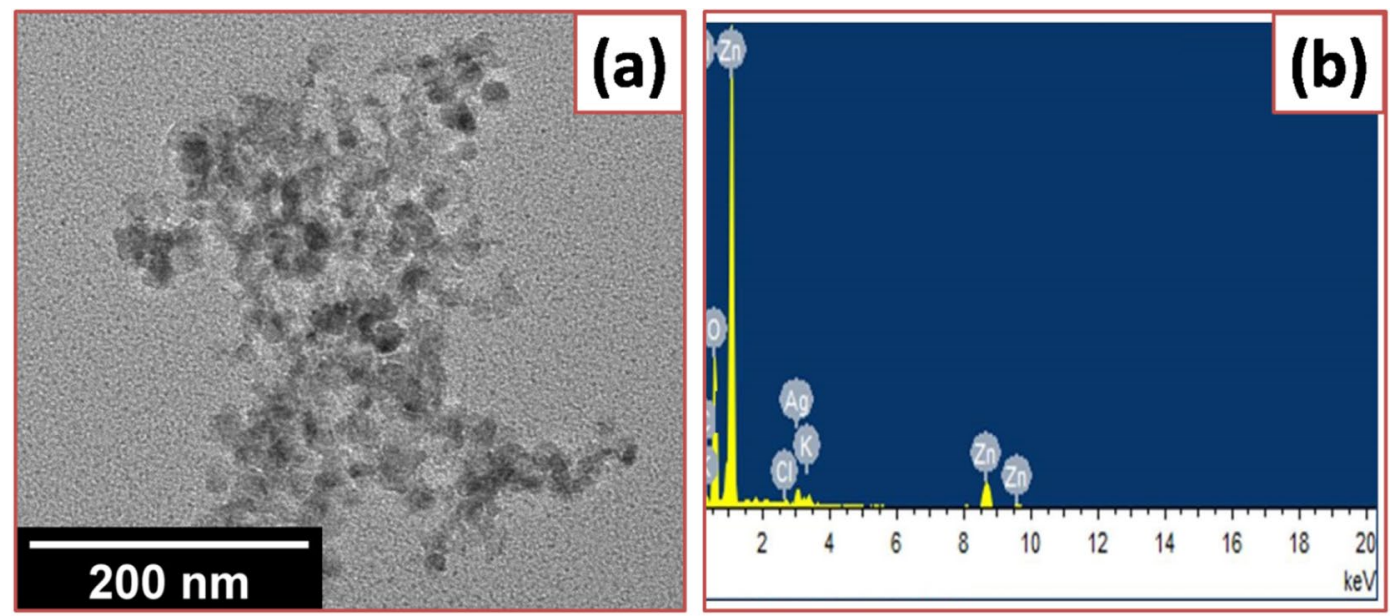

Figure 5. (a) TEM images of $2 \% \mathrm{Ag}-\mathrm{ZnO}$ nanocomposites, and (b) corresponding EDX spectrum.
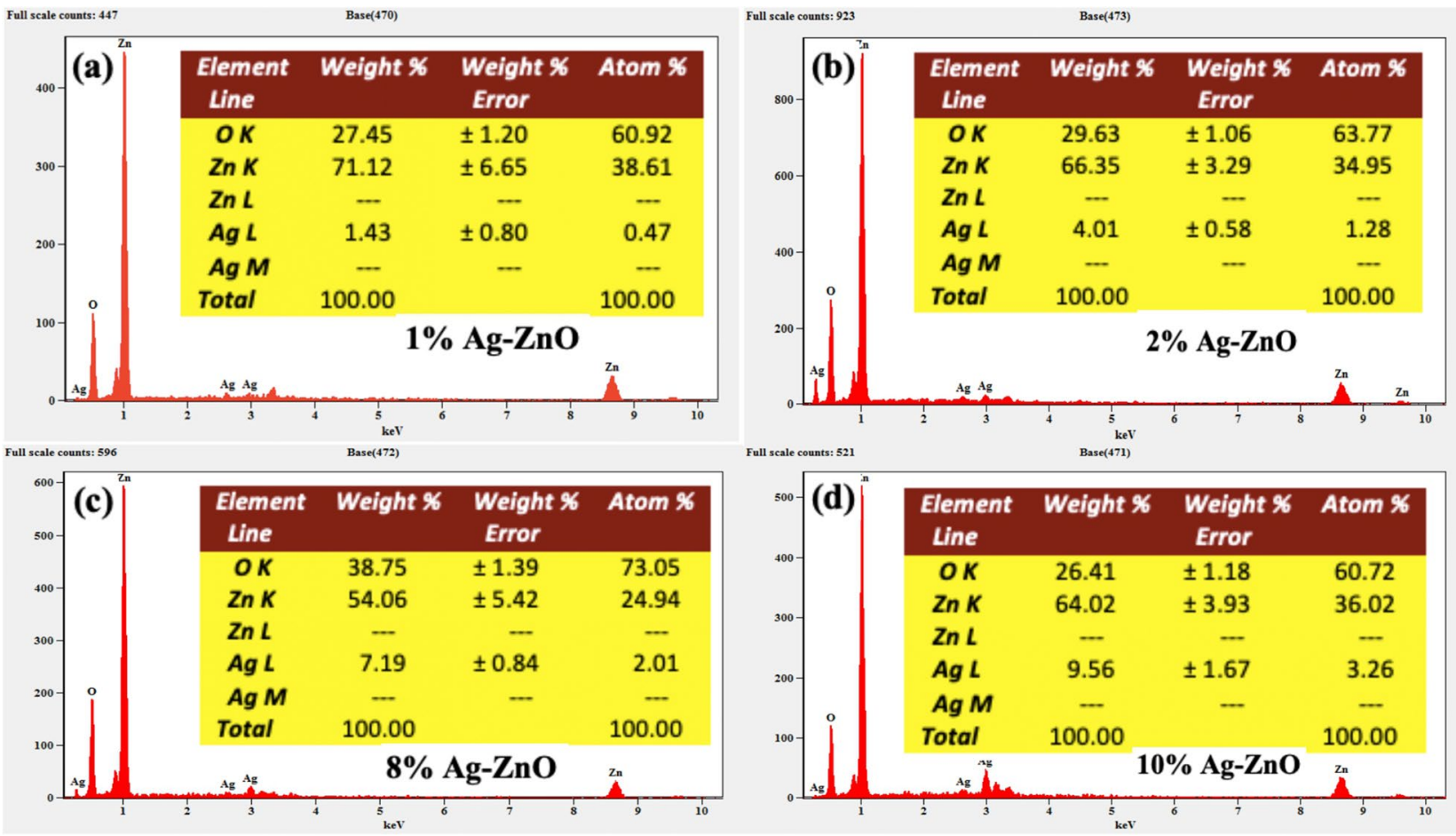

Figure 6. EDX spectra of (a) 1\%, (b) $2 \%$, (c) $8 \%$, and (d) $10 \% \mathrm{Ag}-\mathrm{ZnO}$ nanocomposites.

anchoring of Ag NPs could quench the fluorescence from the $\mathrm{ZnO}$ nanoparticles and prolong electron-hole pair lifetime ${ }^{45,54}$.

The recombination of free excitons of $\mathrm{ZnO}$ could be well explained and related with the NBE emission ${ }^{55}$. Usually, the photogenerated charge carriers separation is directly associated with NBE peaks. For higher recombination rate, the NBE peaks are stronger, which resulted to slower photocatalytic activity ${ }^{54}$. In this work, $2 \%$ $\mathrm{Ag}-\mathrm{ZnO}$ nanocomposites showed a decrease in the NBE intensity, hence, a higher separation rate and lower recombination rate of photo induced charge carriers, which leads to higher photocatalytic activity. While for $8 \% \mathrm{Ag}-\mathrm{ZnO}$ nanocomposites, the intensity was found to increase, showed the lower photocatalytic activity.

Photocatalytic degradation of MB. Photocatalytic properties of Ag- $\mathrm{ZnO}$ nanocomposites with various concentration of $\mathrm{Ag}$ in $\mathrm{ZnO}$ were studied by decomposition of $\mathrm{MB}$. To study the photodegradation of $\mathrm{MB}$, the change of absorbance at $664 \mathrm{~nm}$ wavelength at different time interval was monitored ${ }^{56}$. Figure $8 \mathrm{a}-\mathrm{d}$ depicts the time-dependent absorption spectra of $\mathrm{MB}$ aqueous solutions under visible light irradiation with $\mathrm{Ag}-\mathrm{ZnO}$ nanocomposites. It is clear from the Fig. $8 \mathrm{a}-\mathrm{d}$ that in the presence of $\mathrm{Ag}-\mathrm{ZnO}$ nanocomposites, the maximum 


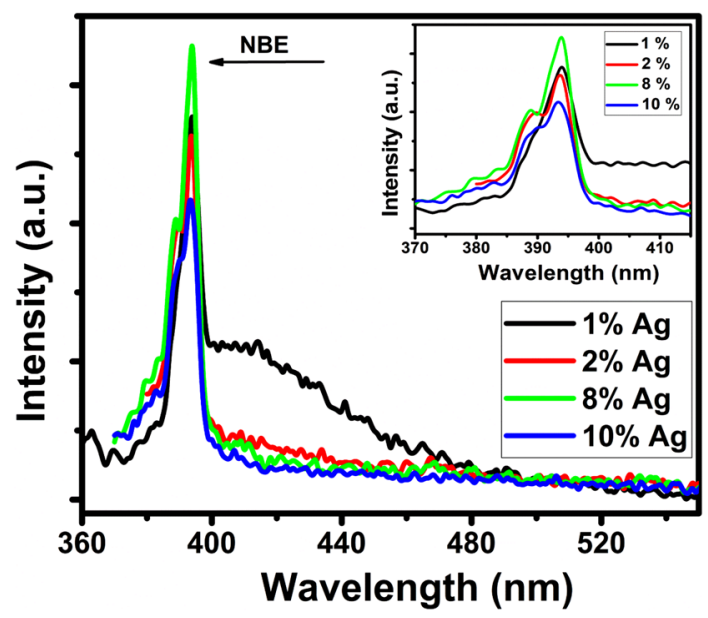

Figure 7. Room temperature PL spectra of Ag- $\mathrm{ZnO}$ nanocomposites.
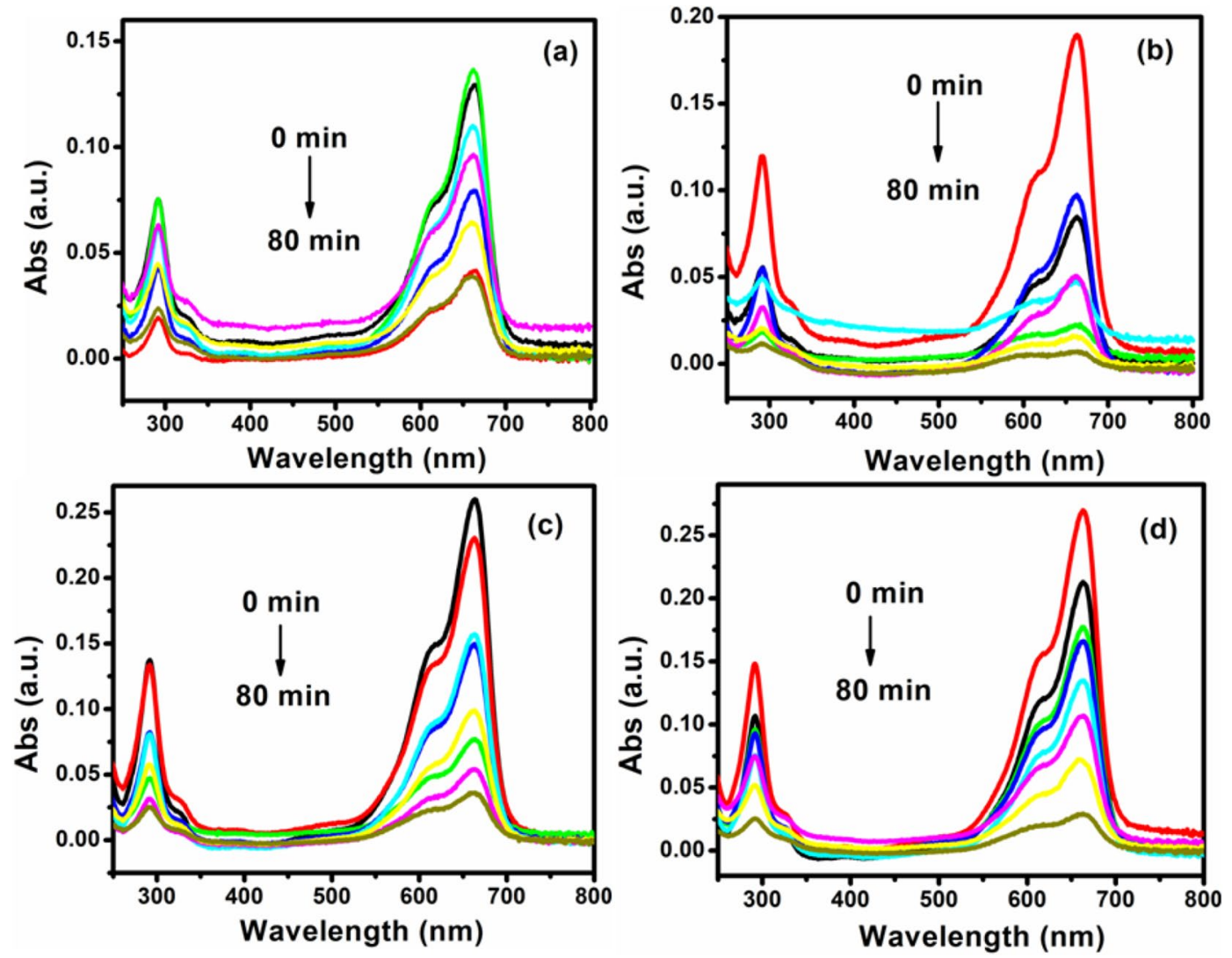

Figure 8. UV-visible absorption spectra of photodegradation of MB in the presence of (a) $1 \%$, (b) $2 \%$, (c) $8 \%$, and (d) $10 \% \mathrm{Ag}-\mathrm{ZnO}$ nanocomposites.

absorption of the $\mathrm{MB}$ solution was found to decrease with illumination time and disappeared almost completely ( 96\%) after irradiation for about $80 \mathrm{~min}$ for $2 \% \mathrm{Ag}-\mathrm{ZnO}$ nanocomposites.

To further evaluate the relationship between photocatalysis and the concentration of $\mathrm{Ag}$ in $\mathrm{ZnO}$, studies on relative concentration $\left(\mathrm{C} / \mathrm{C}_{0}\right)$ of $\mathrm{MB}$ were performed. Figure 9 a shows the relative concentration $\left(\mathrm{C} / \mathrm{C}_{0}\right)$ of $\mathrm{MB}$ as a function of irradiation time for $\mathrm{Ag}-\mathrm{ZnO}$ nanocomposites, where $\mathrm{C}$ corresponds to the concentration of $\mathrm{MB}$ at the irradiation time $(\mathrm{t})$ and $\mathrm{C}_{0}$ is the concentration of the dye before irradiation. When the suspensions were magnetically stirred in the dark for $30 \mathrm{~min}$ to ensure establishment of an adsorption/desorption equilibrium of $\mathrm{MB}$ on the sample surface, only slight decrease in the $\mathrm{MB}$ solution concentration was observed, which demonstrates that the adsorption of $\mathrm{MB}$ on the samples is limited after the adsorption-desorption equilibrium 

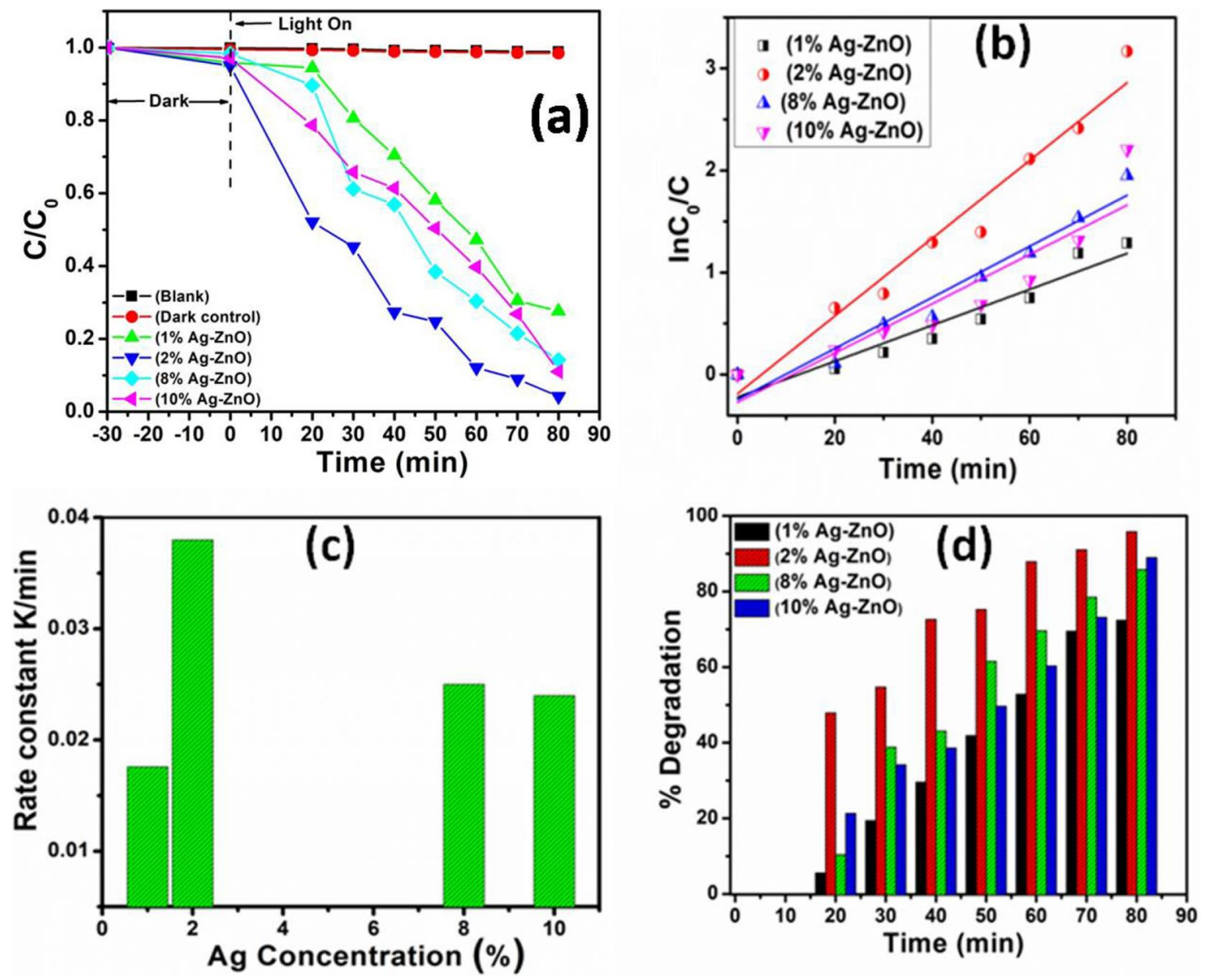

Figure 9. (a) $\mathrm{C} / \mathrm{C}_{0}$ vs time (min) plot for the photodegradation of $\mathrm{MB},(\mathbf{b})$ Kinetic relationship of $\ln \left(\mathrm{C}_{0} / \mathrm{C}\right)$ vs. irradiation time, (c) Plot of rate constant vs. Ag concentration, and (d) Percentage degradation of MB dye as a function of Ag concentration.

is reached. A control experiment revealed negligible decolorization of the dye solution treated with dye solution with photocatalyst in the dark. The extent of decolorization was similar to the blank sample comprising dye solution illuminated with UV light, without photocatalyst. It could be clearly seen from Fig. 9a that for all Ag- $\mathrm{ZnO}$ nanocomposites placed in the solution of $\mathrm{MB}$, the concentration of $\mathrm{MB}$ solution was decreased with irradiation time, which indicates that all the Ag-ZnO nanocomposites show UV-light photocatalytic properties for the degradation of MB. Particularly, the photocatalytic activity of the $2 \% \mathrm{Ag}-\mathrm{ZnO}$ nanocomposites showed excellent activity of degradation for $80 \mathrm{~min}$ of irradiation ac compared with $1 \%, 8 \%$, and $10 \% \mathrm{Ag}-\mathrm{ZnO}$ nanocomposites.

To obtain the reaction rate of the $\mathrm{Ag}-\mathrm{ZnO}$ nanocomposites photocatalysts to understand the role of Ag concentration in $\mathrm{ZnO}$, the kinetic behaviour of these photocatalysts was further studied and the results obtained were shown in Fig. 9b. Generally, the value of $\ln \left(\mathrm{C}_{0} / \mathrm{C}\right)$ and the irradiation time follows linear behaviour ${ }^{45}$. The photocatalytic process can be regarded as pseudo-first-order reaction and the rate equation is expressed as $\ln \left(\mathrm{C}_{0} / \mathrm{C}\right)=\mathrm{kt}$, where, $t$ is reaction time, $k$ is the apparent reaction rate constant, and $\mathrm{C}_{0}$ and $\mathrm{C}$ are the concentration of $\mathrm{MB}$ at time of 0 and $t$, respectively. It is found that the apparent reaction rate constant $\mathrm{K}$ for the degradation of $\mathrm{MB}$ was found to be $1.76 \times 10^{-2} \mathrm{~min}^{-1}, 3.80 \times 10^{-2} \mathrm{~min}^{-1}, 2.49 \times 10^{-2} \mathrm{~min}^{-1}$ and $2.39 \times 10^{-2} \mathrm{~min}^{-1}$, respectively for $1 \% \mathrm{Ag}-\mathrm{ZnO}$ nanocomposites, $2 \%, 8 \%$, and $10 \% \mathrm{Ag}-\mathrm{ZnO}$ nanocomposites, respectively. Figure $9 \mathrm{c}$ shows the relationship between the reaction rate $\mathrm{k}$ and various concentration of $\mathrm{Ag}$ in $\mathrm{ZnO}$. It is clear from Fig. 9c that the reaction rate constant for $2 \% \mathrm{Ag}-\mathrm{ZnO}$ nanocompositesis higher than that of other nanocomposites, which reveals the higher photocatalytic activities of $2 \% \mathrm{Ag}-\mathrm{ZnO}$ nanocomposites.

In order to get more insight on the photodegradation with variable concentration of $\mathrm{Ag}$ in $\mathrm{ZnO}$, the percentage (\%) degradation of $\mathrm{MB}$ dye as a function of $\mathrm{Ag}$ concentration was calculated and shown in Fig. 9d. It is clear from Fig. 9d that the \% degradation increases with the increase in concentration of Ag. The nanocomposites containing $2 \% \mathrm{Ag}$ in $\mathrm{ZnO}$ showed the higher photocatalytic performances of $\sim 96 \%$ within 80 min of irradiation, while only $72 \%, 85 \%$, and $89 \%$ degradation efficiency of MB was observed for $1 \%, 8 \%$, and $10 \% \mathrm{Ag}-\mathrm{ZnO}$ nanocomposites, respectively. This clearly indicates that $2 \% \mathrm{Ag}-\mathrm{ZnO}$ nanocomposites based photocatalyst is more superior to than that of others. These results are in close agreement with the studies observed from PL NBE emission.

In order to estimate the photocatalytic stability of $2 \% \mathrm{Ag}-\mathrm{ZnO}$ nanocomposites photocatalysts, the time courses of photocatalytic degradation of $\mathrm{MB}$ were performed as shown in Fig. 10. Slight decrease of $6 \%$ in degradation of $\mathrm{MB}$ was observed in repeated runs for the photocatalytic reaction of $80 \mathrm{~min}$, which reveals that $2 \%$ 


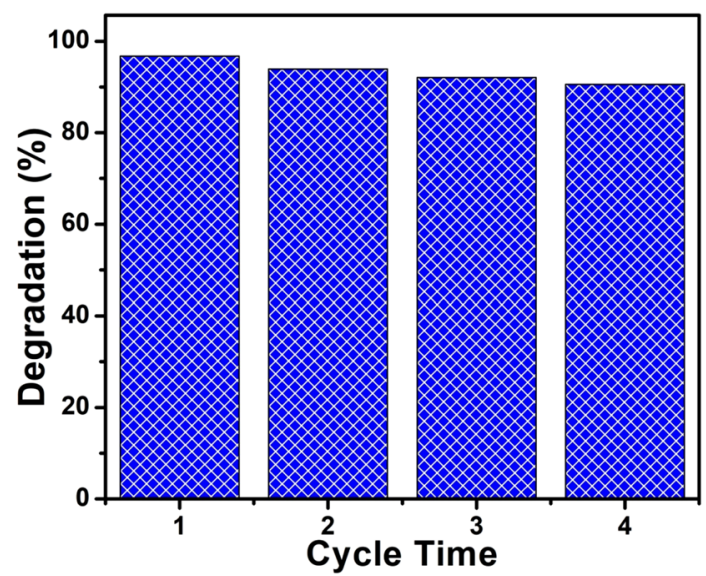

Figure 10. The stability and reusability of $2 \% \mathrm{Ag}-\mathrm{ZnO}$ nanocomposites for photodegradation of $\mathrm{MB}$.

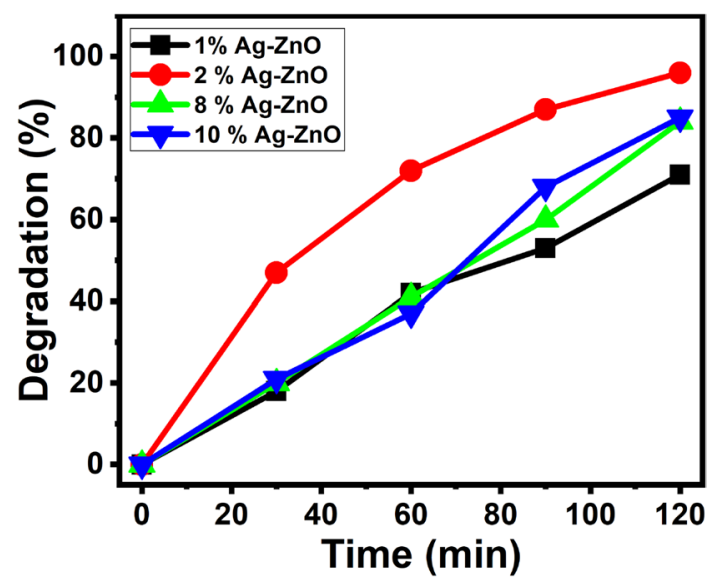

Figure 11. Effect of Ag concentration on photocatalytic degradation of MB.

$\mathrm{Ag}-\mathrm{ZnO}$ nanocomposites have good stability and reusability performance and can be a potential candidate for practical photocatalysis applications.

Effect of silver doping. About $100 \mathrm{~mL}$ of $5 \mathrm{ppm} \mathrm{MB}$ solution was mixed with $10 \mathrm{mg}$ of catalyst and exposed to visible light. Figure 11 shows the degradation of $\mathrm{MB}$ at different concentrations of Ag-ZnO NPs $(1,2,8$ and 10 $\mathrm{Mol} \%$ ). The maximum degradation efficiency was obtained for 2\% Ag-ZnO NPs ( 95\% for $120 \mathrm{~min}$ ) because of the uniform dispersion of $\mathrm{Ag}$ on the surface $\mathrm{ZnO}$ NPs, which enables the separation and migration of charge carriers $^{57}$. Furthermore, the optimum load of Ag concentration was performed for the better degradation rates of MB. At low Ag concentration, lower degradation was noticed, due to the less accessibility of Ag for electrons absorption by the conduction band (CB) of $\mathrm{ZnO}$. Agglomeration of the Ag cluster leads to the blocking of nanocrystals at the higher concentration of Ag loading more than $2 \%$, which results in the lowering of photocatalytic MB degradation ${ }^{58}$. From the outcomes, it is found that the activity is less when Ag loading is more than or less than $2 \%$. The order of increasing photocatalytic activity for dye degradation as follows, $1 \%<8 \%<10 \%<2 \%$ of Ag concentration.

Effect of catalyst dosage. In order to know the optimal catalytic dosage for the efficient degradation of MB, experiment was carried out at different weights $(10,20,30$ and $40 \mathrm{mg})$ of $2 \% \mathrm{Ag}-\mathrm{ZnO}$ NPs by keeping the other parameters constant $(100 \mathrm{~mL}$ of $5 \mathrm{ppm} \mathrm{MB}$ dye) and the results were shown in the Fig. 12. It was observed that the rate of degradation increases, as the concentration of the catalyst load increases from 10 to $20 \mathrm{mg} / 100 \mathrm{~mL}$, this increases the active sites on the surface of the catalyst, which enhances the absorption of number of MB dye. As we further increase the catalyst dosage from 20 to $30 \mathrm{mg} / 100 \mathrm{~mL}$, there is a lower degradation of MB. The fact may be due to the blocking and hindrance of light through the solution on the surface of the catalyst $\mathrm{t}^{59}$. In addition to that high-level concentration of the photocatalytic powder makes the particle aggregation which significantly reduces the active sites on the catalyst surface and hence reduces the efficiency of photocatalytic degradation. 


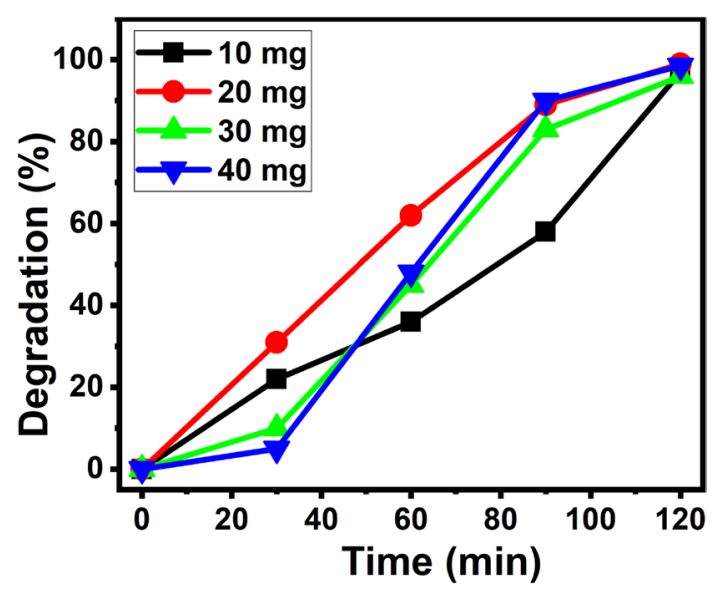

Figure 12. Effect of catalyst dosage on the rate of MB degradation.

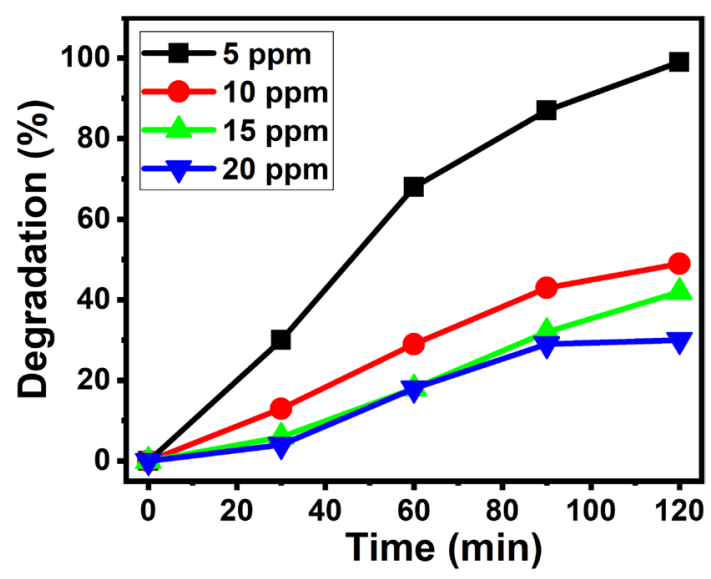

Figure 13. Effect of MB dye concentration on the rate of degradation.

Effect of MB dye concentration. Under the examination of photocatalytic MB degradation, its concentration is very significant parameter. So that, the evaluation of optimal concentration for the efficient oxidation is identified under the set of constant catalytic load $(20 \mathrm{mg} / 100 \mathrm{~mL})$ and varying the dye amount from $5,10,15$ and $20 \mathrm{ppm}$ under the influence of visible irradiation. From Fig. 13, it is observed that as the concentration increases from 5 to $20 \mathrm{ppm}$, the rate of degradation decreases. This may be due to the lowering of light penetrating power, when the dye concentration is enhanced, which lowers the production of photogenerated-electrons and holes ultimately leads to lowering the rate of photodegradation ${ }^{60}$.

Effect of $\mathrm{pH}$ on dye degradation. The study of effect of $\mathrm{pH}$ on the degradation of $\mathrm{MB}$ dye using $2 \% \mathrm{Ag}-\mathrm{ZnO}$ NPs are shown in Fig. 14. The highest degradation efficiency of MB shown under basic condition $(\mathrm{pH} 8,10,12)$ and lower activity was observed under acidic condition. This study was confirmed that the MB showing more degradation in the alkaline condition specifically at $\mathrm{pH} 8$ and this was due to the adsorption of more number of $\mathrm{MB}$ dyes on selected catalyst. In presence of acidic medium, MB dye shows least degradation, which is due to the dissolution of $\mathrm{Ag}-\mathrm{ZnO}$ derivatives and forms the corresponding salts ${ }^{61}$.

The increase in the rate of degradation of $\mathrm{MB}$ dye under basic medium is mainly due to the formation of more number of $\bullet \mathrm{OH}$ from the ${ }^{-} \mathrm{OH}$ rather than $\mathrm{H}_{2} \mathrm{O}$. Hence, the rate of degradation of $\mathrm{MB}$ is more. Further, adsorption of more number of $\mathrm{MB}$ onto catalyst in basic $\mathrm{pH}$ caused by the reduction and oxidation between the $\mathrm{MB}$ dye and catalyst. Hence, the photocatalytic dye degradation is low at acidic $\mathrm{pH}$ compared to basic $\mathrm{pH}$ and similar results of photocatalytic degradation were found for $\mathrm{ZnO}$ analogues ${ }^{62}$.

$$
\begin{gathered}
\mathrm{h}_{\mathrm{VB}+}+\mathrm{OH}^{-} \rightarrow \mathrm{OH} \bullet \\
\mathrm{MB}+\mathrm{h}_{\mathrm{VB}+} \rightarrow \text { oxidation products } \\
\mathrm{MB}+\mathrm{e}_{\mathrm{CB}-} \rightarrow \text { reduction products }
\end{gathered}
$$




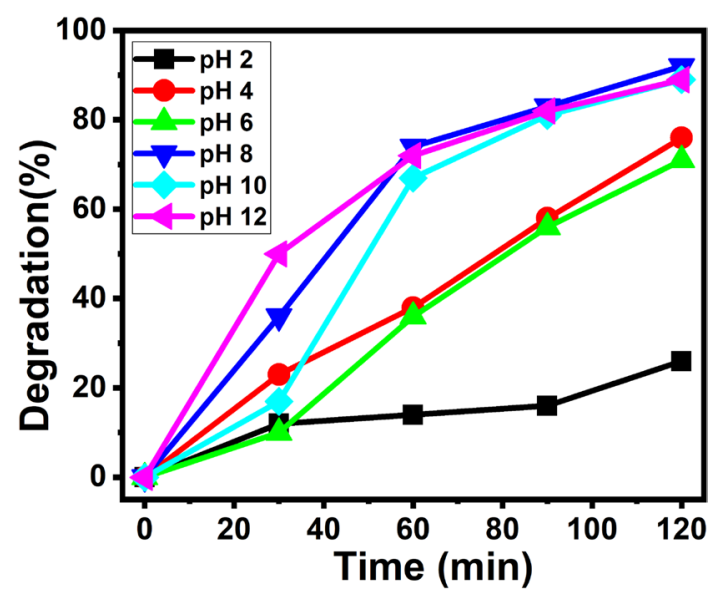

Figure 14. Effect of $\mathrm{pH}$ on the rate of degradation.

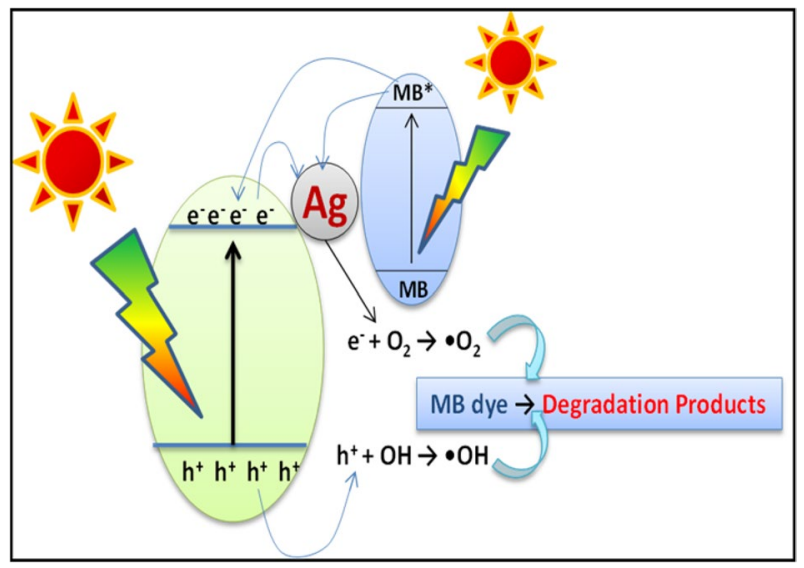

Figure 15. Schematic representation of $\mathrm{MB}$ dye degradation by Ag-ZnO Photocatalyst.

Mechanism of degradation of $M B$ using $2 \% A g-Z n O N P s$. When the light of certain wavelength (which has equal to or higher than the wavelength of band gap of the catalyst) absorbed byAg- $\mathrm{ZnO}$ nanocomposites, there will be jumping of electrons from valance band (VB) to conduction band (CB). This creates the holes at the VB, which are electron deficient species. At the same time, the electrons are more gathered at the $\mathrm{CB}$, which are electron rich species. The electrons at the $\mathrm{CB}$ reacts with $\mathrm{O}_{2}$ to form $\cdot \mathrm{O}_{2}{ }^{-}$and holes at the $\mathrm{VB}$ reacts with water to form $\cdot \mathrm{OH}$. These created intermediates are highly reactive as well as strong oxidizing in nature and oxidizes the $\mathrm{MB}$ dye into to $\mathrm{CO}_{2}, \mathrm{H}_{2} \mathrm{O}$ and corresponding mineral acids as degradation products. These results recommend that Ag NPs anchored on the surface of $\mathrm{ZnO}$ might help in increasing the formation rate of $\bullet \mathrm{O}_{2}{ }^{-}$and $\bullet \mathrm{OH}$ reactive species, and concurrently help the degradation of organic pollutants. A probable mechanism of $\mathrm{MB}$ degradation by $\mathrm{Ag}-\mathrm{ZnO}$ is shown in below scheme, and graphically represented in Fig. 15.

$$
\begin{gathered}
\mathrm{Ag}-\mathrm{ZnO}+\mathrm{h} v \rightarrow \mathrm{Ag}-\mathrm{ZnO}\left(\mathrm{h}_{\mathrm{vb}}^{+}+\mathrm{e}_{\mathrm{cb}}^{-}\right) \\
\mathrm{OH}-_{\text {ads }}+\mathrm{h}+_{\mathrm{vb}} \rightarrow \mathrm{OH} \cdot \text { ads }(\text { in basic medium }) \\
\mathrm{MB}+\mathrm{OH} \cdot{ }_{\mathrm{ads}} \rightarrow \text { dye degradation }
\end{gathered}
$$

\section{Conclusions}

In conclusion, different nanoparticles of Ag-ZnO NPs were successfully synthesized through environmental friendly novel green method using potato waste. XRD and FTIR studies reveal that Ag-ZnO nanocomposites have highly crystalline nature, good chemical characteristics and exhibit perfect morphological entity. The assynthesized $2 \% \mathrm{Ag}-\mathrm{ZnO}$ nanocomposites possess maximum catalytic activity ( 96\%) to degrade the MB dye within $80 \mathrm{~min}$ by visible light, which demonstrates the potential application towards the wastewater purification with environmental friendly material. This enhanced photocatalytic performance of $2 \% \mathrm{Ag}-\mathrm{ZnO}$ nanocomposites 
was mainly ascribed to the decreased recombination rate of photogenerated charge carriers stimulated by the anchoring of AgNPs on the surface of $\mathrm{ZnO}$. These photocatalysts can be applied as fruitful photocatalytic material on industrial scale for the exploitation of structurally stable and complex dyestuff. This study offers a green and non-toxic method containing biomaterials to synthesize various nanomaterials using this eco-friendly preparation route which could be extend to use other natural sources including rice, corn and other grains.

Received: 5 September 2020; Accepted: 4 November 2020

Published online: 19 November 2020

\section{References}

1. Costa, D., Burlandoc, P. \& Priadi, C. The importance of integrated solutions to flooding and water quality problems in the tropical megacity of Jakarta. Sustain. Cities Soc. 20, 199-209 (2016).

2. Palmate, S. S., Pandey, A., Kumar, D., Pandey, R. P. \& Mishra, S. K. Climate change impact on forest cover and vegetation in Betwa Basin. India. Appl. Water Sci. 7, 1-12 (2017).

3. Clemens, S. \& Ma, J. F. Toxic heavy metal and metalloid accumulation in crop plants and foods. Annu. Rev. Plant Biol. 67, 489-512 (2016).

4. Perelo, L. W. Review: in situ and bioremediation of organic pollutants in aquatic sediments. J. Hazard. Mater. 177, 81-89 (2010).

5. Gaini, L. E., Lakraimi, M., Sebbar, E., Meghea, A. \& Bakasse, M. Removal of indigo carmine dye from water to $\mathrm{Mg}$-Al- $\mathrm{CO}_{3}$-calcined layered double hydroxides. J. Hazard. Mater. 161, 627-632 (2009).

6. Ayed, L., Mahdhi, A., Cheref, A. \& Bakhrouf, A. Decolorization and degradation of azo dye Methyl Red by an isolated Sphingomonaspaucimobilis: biotoxicity and metabolites characterization. Desalination 274, 272-277 (2011).

7. Haider, S. et al. Natural polymers supported copper nanoparticles for pollutants degradation. Appl. Surf. Sci. 387, 1154-1161 (2016).

8. Lindholm-Lehto, P. C., Knuutinen, J. S., Ahkola, H. S. \& Herve, S. H. Refractory organic pollutants and toxicity in pulp and paper mill wastewaters. Environ. Sci. Pollut. Res. 22, 6473-6499 (2015).

9. Bagal, M. V. \& Gogate, P. R. Wastewater treatment using hybrid treatment schemes based on cavitation and Fenton chemistry: a review. Ultrason. Sonochem. 21, 1-14 (2014).

10. Mbamba, C. K., Batstone, D. J., Alsina, X. F. \& Tait, S. A generalised chemical precipitation modelling approach in wastewater treatment applied to calcite. Water Res. 68, 342-353 (2015).

11. Christensen, M. L., Keiding, K., Nielsen, P. H. \& Jorgensen, M. K. Dewatering in biological wastewater treatment: a review. Water Res. 82, 14-24 (2015).

12. Kumar, K. Y., Muralidhara, H. B., Nayaka, Y. A., Balasubramanyam, J. \& Hanumanthappa, H. Low-cost synthesis of metal oxide nanoparticles and their application in adsorption of commercial dye and heavy metal ion in aqueous solution. Powder Tech. 246, $125-136$ (2013).

13. Zangeneh, H., Zinatizadeh, A. A. L., Habibi, M., Akia, M. \& Isa, M. H. Photocatalytic oxidation of organic dyes and pollutants in wastewater using different modified titanium dioxides: a comparative review. J. Ind. Eng. Chem. 26, 1-36 (2015).

14. Mingxin, L. et al. Photocatalytic performance and mechanism research of $\mathrm{Ag} / \mathrm{HSTiO}_{2}$ on degradation of methyl orange. ACS Omega 5, 21451-21457 (2020).

15. Guan, R., Zhai, H. \& Sun, D. Effects of Ag doping content and dispersion on the photocatalytic and antibacterial properties in ZnO nanoparticles. Chem. Res. Chin. Univ. 35, 271-276 (2019).

16. Jiaxin, L. et al. Preparation and photocatalytic performance of dumbbell $\mathrm{Ag}_{2} \mathrm{CO}_{3}-\mathrm{ZnO}$ heterojunctions. ACS Omega 5, 570-577 (2020).

17. Jing, L. et al. Facile fabrication of magnesium peroxide with different morphologies via the isomorphic transformation of magnesium oxide for Fenton-like degradation of methylene blue. Colloids Surf. A Physicochem. Eng. Aspects 607, 125499 (2020).

18. Jing, L. et al. Facile one-step synthesis of 3D hierarchical flower-like magnesium peroxide for efficient and fast removal of tetracycline from aqueous solution. J. Hazard. Mater. 397, 122877 (2020).

19. Pei, C. et al. Facile one-pot fabrication of $\mathrm{ZnO}$ particles for the efficient Fenton-like degradation of tetracycline. J. Alloys Compd. 834, 155220 (2020).

20. Yamei, Y. et al. Enhanced dark adsorption and visible-light-driven photocatalytic properties of narrower-band-gap $\mathrm{Cu}_{2} \mathrm{~S}$ decorated $\mathrm{Cu}_{2} \mathrm{O}$ nanocomposites for efficient removal of organic pollutants. J. Hazard. Mater. 384, 121302 (2020).

21. Doudou, W. et al. Highly pure $\mathrm{MgO}_{2}$ nanoparticles as robust solid oxidant for enhanced Fenton-like degradation of organic contaminants. J. Hazard. Mater. 374, 319-328 (2019).

22. Gupta, V. K., Kumar, R., Nayak, A., Saleh, T. A. \& Barakat, M. A. Adsorptive removal of dyes from aqueous solution onto carbon nanotubes: a review. Adv. Colloid Interface Sci. 193-194, 24-34 (2013).

23. Konicki, W., Aleksandrzak, M., Moszynski, D. \& Mijowska, E. Adsorption of anionic azo dyes from aqueous solutions onto graphene oxide: equilibrium, kinetic and thermodynamic studies. J. Colloid Interface Sci. 496, 188-200 (2017).

24. Liu, G. et al. Unique electronic structure induced high photoreactivity of sulfur-doped graphiticC ${ }_{3}$ N4. J. Am. Chem. Soc. 132, $11642-11648$ (2010).

25. Haibin, L., Xuechen, D., Guocong, L. \& Xiaoqi, L. Photochemical synthesis and characterization of Ag/ $/ \mathrm{TiO}_{2}$ nanotube composites. J. Mater. Sci. 43, 1669-1676 (2008).

26. Jin, Q., Fujishima, M. \& Tada, H. Visible-light-active ironoxide-modified Anatase Titanium(IV) Dioxide. J. Phys. Chem. C 115, 6478-6483 (2011).

27. Rashad, M. M. et al. Photocatalytic decomposition of dyes using $\mathrm{ZnO}$ doped $\mathrm{SnO}_{2}$ nanoparticles prepared by solvothermal method. Arab. J. Chem. 7, 71-77 (2014).

28. Ahmad, M. \& Zhu, J. ZnO based advanced functional nanostructures: synthesis, properties and applications. J. Mater. Chem. 21, 599-614 (2011).

29. Dong, Z. H. et al. Accurate control of multishelled $\mathrm{ZnO}$ hollow microspheres for dye-sensitized solar cells with high efficiency. Adv. Mater. 24, 1046-1049 (2012).

30. Wagata, H. et al. Single-step fabrication of $\mathrm{ZnO}$ rod arrays on a nonseeded glass substrate by a spin-spray technique at $90^{\circ} \mathrm{C}$. Cryst. Growth Des. 10, 3502-3507 (2010).

31. Yang, L. Y. et al. Microwave assisted preparation, characterization and photocatalytic properties of a dumbbell-shaped $\mathrm{ZnO}$ photocatalyst. J. Hazard. Mater. 179, 438-443 (2010).

32. Liu, X. H. et al. 3D hierarchically porous $\mathrm{ZnO}$ structures and their functionalization by Au nanoparticles for gas sensors. J. Mater. Chem. 21, 349-356 (2011).

33. $\mathrm{Hu}, \mathrm{Z}$., Chen, S. \& Peng, S. Preparation of nanosize $\mathrm{Cu}-\mathrm{ZnO} / \mathrm{Al}_{2} \mathrm{O}_{3}$ catalyst for methanol synthesis by phase transfer with metal surfactant: 1. A study of preparation conditions. J. Colloid Interface Sci. 182, 457-460 (1996).

34. Kostedt, W. L., Ismail, A. A. \& Mazyck, D. W. Impact of heat treatment and composition of $\mathrm{ZnO}-\mathrm{TiO}_{2}$ nanoparticles for photocatalytic oxidation of an Azo dye. Ind. Eng. Chem. Res. 47, 1483-1487 (2008). 
35. Georgekutty, R., Seery, M. K. \& Pillai, S. C. A highly efficient Ag-ZnO photocatalyst: synthesis, properties, and mechanism. J. Phys. Chem. C 112, 13563-13570 (2008).

36. Chen, C. et al. Enhanced Raman scattering and photocatalytic activity of Ag/ZnO heterojunction nanocrystals. Dalton Trans. 40, 9566-9570 (2011).

37. Deng, Q. et al. Ag nanoparticle decorated nanoporous $\mathrm{ZnO}$ microrods and their enhanced photocatalytic activities. ACS Appl. Mater. Interfaces 4, 6030-6037 (2012).

38. Vigneshwaran, N., Nachane, R., Balasubramanya, R. \& Varadarajan, P. A novel one-pot 'green'synthesis of stable silver nanoparticles using soluble starch. Carbohydr. Res. 341, 2012-2018 (2006).

39. Singh, G. et al. Synthesis of $\mathrm{ZnO}$ nanoparticles using the cell extract of the cyanobacterium, Anabaena strain L31 and its conjugation with UV-B absorbing compound shinorine. J. Photochem. Photobiol. B Biol. 138, 55-62 (2014).

40. Azizi, S., Ahmad, M. B., Namvar, F. \& Mohamad, R. Green biosynthesis and characterization of zinc oxide nanoparticles using brown marine macroalga Sargassum muticum aqueous extract. Mater. Lett. 116, 275-277 (2014).

41. Fahad, A. A. et al. Synthesis of nanocauliflowe $\mathrm{rZnO}$ photocatalyst by potato waste and its photocatalytic efficiency against dye. J. Mater. Sci. Mater. Electron. 31, 11538-11547 (2020).

42. Fahad, A. A. et al. Green synthesis of $\mathrm{ZnO}$ nanostructures using Salvadora Persica leaf extract: applications for photocatalytic degradation of methylene blue dye. Crystals 10, 441 (2020).

43. Zhang, G., Shen, X. \& Yang, Y. Facile synthesis of monodisperse porous ZnO spheres by a soluble starch-assisted method and their photocatalytic activity. J. Phys. Chem. C 115, 7145-7152 (2011).

44. Renault, F., Morin, C. N., Gimbert, F., Badot, P. M. \& Crini, G. Cationized starch-based material as a new ion-exchanger adsorbent for the removal of CI Acid Blue 25 from aqueous solutions. Bioresour. Technol. 99, 7573-7586 (2008).

45. Ahmed, F., Arshi, N., Anwar, M. S., Rehan, D. \& Bon, H. K. Morphological evolution of ZnO nanostructures and their aspect ratio-induced enhancement in photocatalytic properties. RSC Adv. 4, 29249-29263 (2014).

46. Binks, D. J. \& Grimes, R. W. Incorporation of monovalent ions in $\mathrm{ZnO}$ and their influence on varistor degradation. J. Am. Ceram. Soc. 76, 2370-2372 (1993).

47. Acarbas, O., Suvaci, E. \& Dogan, A. Preparation of nanosized tin oxide $\left(\mathrm{SnO}_{2}\right)$ powder by homogeneous precipitation. Ceram. Int. 33, 537-542 (2007).

48. Rauf, M. A. et al. Synergistic effect of diallylsulphide with zinc oxide nanorods: a novel and effective approach for treatment of acute dermatitis in model animals. Front. Microbiol. 9, 586 (2018).

49. JingL, Q., Xu, Z. L., Sun, X. J., Shang, J. \& Cai, W. M. The surface properties and photocatalytic activities of ZnO ultrafine particles. Appl. Surf. Sci 180, 308-314 (2001).

50. Wang, J. et al. Largely improved photocatalytic properties of Ag/tetrapod-like $\mathrm{ZnO}$ nanocompounds prepared with different PEG contents. Appl. Surf. Sci. 257, 7763-7770 (2011).

51. Wang, L. et al. Microwave-assisted synthesis and photocatalytic performance of Ag-doped hierarchical $\mathrm{ZnO}$ architectures. Mater. Lett. 79, 277-280 (2012).

52. Tan, T. et al. Two-step preparation of Ag/tetrapod-like $\mathrm{ZnO}$ with photocatalytic activity by thermal evaporation and sputtering. Mater. Chem. Phys. 111, 305-308 (2008).

53. Nagarajua, G. et al. Electrochemical heavy metal detection, photocatalytic, photoluminescence, biodieselproduction and antibacterial activities of Ag-ZnO nanomaterial. Mater. Res. Bull. 94, 54-63 (2017).

54. Liqiang, J. et al. Review of photoluminescence performance of nano-sized semiconductor materials and its relationships with photocatalytic activity. Sol. Energy Mater. Sol. Cells 90, 1773-1787 (2006).

55. Wu, J. J. \& Liu, S. C. Low-temperature growth of well-aligned $\mathrm{ZnO}$ nanorods by chemical vapor deposition. Adv. Mater. 14, 215-2018 (2002).

56. Basavalingiah, K. R., Harishkumar, S., Nagaraju, G. \& Rangappa, D. C. Highly porous, honeycomb like Ag-ZnO nanomaterials for enhanced photocatalytic and photoluminescence studies: green synthesis using Azadirachtaindica gum. SN Appl. Sci. 1, 935 (2019).

57. Udayabhanu., Reddy, N.L., Shankar, M.V., Sharma, S. C. \& Nagaraju, G. One-pot synthesis of $\mathrm{Cu}-\mathrm{TiO}_{2} / \mathrm{CuO}$ nanocomposite: application to photocatalysis for enhanced $\mathrm{H}_{2}$ production, dye degradation \& detoxification of $\mathrm{Cr}$ (VI). Int. J. Hydrog. Energy 45, 7813-7828 (2020).

58. Buvaneswari, K., Karthiga, R., Kavitha, B., Rajarajan, M. \& Suganthi, A. Effect of $\mathrm{FeWO}_{4}$ doping on the photocatalytic activity of ZnO under visible light irradiation. Appl. Surf. Sci. 356, 333-340 (2015).

59. Udayabhanu et al. Green, nonchemical route for the synthesis of $\mathrm{ZnO}$ superstructures, evaluation of its applications toward photocatalysis, photoluminescence, and biosensing. Cryst. Growth Des. 16, 6828-6840 (2016).

60. Chiang, Y. J. \& Lin, C. C. Photocatalytic decolorization of methylene blue in aqueous solutions using coupled $\mathrm{ZnO} / \mathrm{SnO}_{2}$ photocatalysts. Powder Tech. 246, 137-143 (2013).

61. Behnajady, M. A., Modirshahla, N. \& Hamzavi, R. Kinetic study on photocatalytic degradation of C.I. Acid Yellow 23 by ZnO photocatalyst. J. Hazard. Mater. 133, 226-232 (2006).

62. Wahab, R., Hwang, I. H., Kim, Y. S. \& Shin, H. S. Photocatalytic activity of zinc oxide micro-flowers synthesized via solution method. Chem. Eng. J. 168, 359-366 (2011).

\section{Acknowledgements}

The authors extend their appreciation to the Deanship of Scientific Research at King Saud University for funding this work through the research group No. RGP-1441-305.

\section{Author contributions}

Conceptualization, F.A.A. and A.A.A.; Data curation, H.S.A.; A.A.A.; Formal analysis, N.A.-Z.; Funding acquisition, F.A.A. Resources, N.A.; Visualization, A.E.M.; Writing-original draft, N.A.; Writing-review \& editing, F.A.A., A.A.A., A.E.M., N.A.-Z., H.S.A., A.A.A.

\section{Competing interests}

The authors declare no competing interests.

\section{Additional information}

Correspondence and requests for materials should be addressed to F.A.A.

Reprints and permissions information is available at www.nature.com/reprints.

Publisher's note Springer Nature remains neutral with regard to jurisdictional claims in published maps and institutional affiliations. 
(c) (i) Open Access This article is licensed under a Creative Commons Attribution 4.0 International cc) License, which permits use, sharing, adaptation, distribution and reproduction in any medium or format, as long as you give appropriate credit to the original author(s) and the source, provide a link to the Creative Commons licence, and indicate if changes were made. The images or other third party material in this article are included in the article's Creative Commons licence, unless indicated otherwise in a credit line to the material. If material is not included in the article's Creative Commons licence and your intended use is not permitted by statutory regulation or exceeds the permitted use, you will need to obtain permission directly from the copyright holder. To view a copy of this licence, visit http://creativecommons.org/licenses/by/4.0/.

(C) The Author(s) 2020 